\title{
Ensino Médio Integrado e Juventudes: desafios e projetos de futuro
}

\author{
Celecina Veras Sales' \\ Maria Aurilene de Deus Moreira Vasconcelos"
}

'Universidade Federal do Ceará (UFC), Fortaleza/CE - Brasil "Secretaria de Educação do Estado do Ceará, Fortaleza/CE - Brasil

RESUMO - Ensino Médio Integrado e Juventudes: desafios e projetos de futuro. Os encontros entre o Ensino Médio Integrado e projetos de futuro dos jovens egressos da Escola Estadual de Educação Profissional Paulo Petrola apresentam desafios para a educação escolar. Enquanto a escola estudada tem como proposta pedagógica a integração curricular expressa na concepção de formação humana, capaz de formar jovens cidadãos autônomos, a cidade oferece percursos sinuosos e caminhos incertos. Percebemos através de entrevistas narrativas que o currículo inovador da escola tem uma repercussão afirmativa na trajetória desses jovens. O ingresso e a permanência dos jovens no ensino médio transitam entre os desejos de ingressar no ensino superior, entrar no mercado de trabalho e às vezes se perder pelas vicissitudes de suas vidas.

Palavras-chave: Jovens. Projeto de Futuro. Escola. Ensino Médio.

ABSTRACT - Integrated Secondary Education and Youth: challenges and projects for the future. The encounters between the Integrated Secondary Education and the projects for the future of former students of Paulo Petrola Professional Education State School challenge school education. While the pedagogical proposal of the investigated school is the curriculum integration expressed in the conception of human formation, able to educate the youth to be autonomous young citizens, the city offers winding paths and uncertain ways. By means of narrative interviews, we have identified that the innovative school curriculum has an affirmative repercussion on the trajectory of these young students. The entrance and the permanence of the youth in the secondary education are marked by the desire to enter higher education, come into the work market and, sometimes, to lose themselves in the vicissitudes of their lives.

Keywords: Youth. Project for the Future. School. Secondary Education.

Educação \& Realidade, Porto Alegre, v. 41, n. 1, p. 69-90, jan./mar. 2016. 


\section{Introdução}

Jovens pobres, sobreviventes de cidades divididas, a enfrentar incertezas de um tempo de turbulenta crise política e econômica: assim pode ser retratada a vida de tantos/as jovens em diversos lugares do mundo. Esse cenário, local e global, conecta histórias e perspectivas de vidas de jovens das metrópoles. Para essa juventude se coloca insegurança e desafios, “[...] pois o futuro é uma referência opaca que solapa a ausência de opções frente a seus problemas fundamentais” (Arce, 2009, p. 20, tradução livre).

Os contextos sociais, políticos e econômicos, mediados pela aleatoriedade e contingências da sociedade contemporânea, interferem sobremaneira nas relações da juventude com a educação escolar e perspectivas juvenis e, por conseguinte, nas trajetórias dos/as jovens. Este estudo objetiva conhecer as perspectivas e projetos de futuro dos jovens egressos de uma escola de Ensino Médio Integrado (EMI), a Escola Estadual de Educação Profissional Paulo Petrola, a qual tem como proposta pedagógica a integração curricular expressa na concepção de formação humana, visando à formação omnilateral do sujeito. A proposta ainda preconiza um Ensino Médio que articule cultura, conhecimento, tecnologia e trabalho e que seja capaz de formar jovens cidadãos autônomos.

Os jovens e as jovens desta pesquisa fazem parte desse tempo e espaço, e suas trajetórias são marcadas pelo modo de vida que se instaura em seu bairro, a Barra do Ceará, considerado um dos bairros mais violentos da cidade de Fortaleza-Ceará, a quinta maior cidade brasileira. A Barra do Ceará localiza-se no extremo oeste da cidade de Fortaleza, região litorânea, com setenta e seis mil e duzentos (76.200) habitantes. É um dos bairros de maior população jovem da capital, com vinte e dois mil quinhentos e setenta e sete (22.577) jovens, sendo sete mil trezentos e oitenta e dois (7.382) na faixa etária de 15 a 19 anos, oito mil e quinze (8.015) na faixa etária de 20 a 24 anos, sete mil cento e oitenta (7.180) na faixa etária de 25 a 29 anos (IBGE, 2012).

O bairro ocupa o primeiro lugar da cidade em relação às taxas de jovens analfabetos da população acima de 15 anos de idade. É também nessa região que se concentram as maiores proporções de jovens na extrema pobreza (IBGE, 2012).

A pesquisa foi realizada entre os anos de 2012 e 2014 e teve como objetivo conhecer os projetos de futuro dos jovens egressos da Escola Estadual de Educação Profissional Paulo Petrola (EEEPPP) através de narrativas de suas histórias de vida. A Escola localiza-se na Barra do Ceará e seu entorno caracteriza-se por ser uma região de muita pobreza e miséria, com altos índices de violência, criminalidade, tráfico de drogas e prostituição de menores. A população, em sua maioria, trabalha nas áreas da construção civil, da pesca artesanal, do trabalho doméstico e do pequeno comércio, caracterizados como mercado informal.

$70 \quad$ Educação \& Realidade, Porto Alegre, v. 41, n. 1, p. 69-90, jan./mar. 2016. 
O início das escolas de ensino médio profissionalizantes do Estado do Ceará se deu após a adesão do Estado à proposta do Ensino Médio Integrado, em vigor através do Decreto no 5154/04, que traz para a educação brasileira a possibilidade de integrar o ensino médio à educação profissional técnica de nível médio. Em 2007, o Programa BRASIL PROFISSIONALIZADO, surgiu para fortalecer as redes estaduais de educação profissional e tecnológica, ofertando incentivos e apoio financeiro a todos os estados da federação que aderissem ao Programa.

Em 2008 o Governo do Estado do Ceará aderiu à proposta do Ensino Médio Integrado instituindo, no referido ano, as Escolas Estaduais de Educação Profissional através da Lei no 14.273, de 19/12/2008 (Ceará, 2013).

As escolas de ensino médio profissionalizantes do Ceará laboração em tempo integral e tem uma proposta pedagógica específica que contempla em sua formação disciplinas em que os/as alunos/as são estimulados a desenhar seus projetos de vida, a elaborar projeções de futuro, a fazer reflexões de suas posturas diante do mundo e a buscar conhecer a realidade em que vivem. A disciplina Projeto de Vida faz parte da sua Matriz Curricular, assim como outras disciplinas que nesta mesma perspectiva integram os componentes curriculares das Escolas Estaduais de Educação Profissional do Ceará, entre elas: Mundo do Trabalho; Formação para Cidadania; Temáticas, Práticas e Vivências; Projetos Interdisciplinares.

Assim, a meta da escola é o futuro, bem como a sua finalidade: formar futuros cidadãos, pais de família, profissionais, líderes, dirigentes. Nessa compreensão, os jovens seriam seres em trânsito, onde o seu presente estaria atrelado ao seu futuro. Segundo Pais (2006), o futuro é o tempo que parece legitimar a razão de ser do sistema de ensino - esta é a crença generalizada, ao predicar-se que ele permite a “[...] formação dos futuros homens do amanhã".

A divulgação das escolas profissionalizantes na mídia local gerou expectativas sobre o ingresso imediato ao mercado de trabalho. Dessa forma, os pais e mães têm na escola a crença de que seus/suas filhos/ as terão um futuro melhor que o seu, e que seguirão profissões diferentes das suas: pedreiros, serventes, pescadores, domésticas. Os/as jovens também vislumbravam através da escola um futuro promissor, como o acesso a faculdade, emprego fixo, formal e de carteira assinada.

Em uma sociedade em crise, desemprego, subemprego, mercado volátil, instabilidades, há lugar para sonhar e projetar futuro? É dentro desse contexto que se iniciam as inquietações, as quais motivaram a buscar a compreensão do papel social que a EEEPPP traz para a formação humana e profissional dos/as jovens. Dentre os diversos desafios, destacamos: A escola estaria criando falsas expectativas naqueles/as jovens? Onde estão os/as jovens após concluírem o ensino médio? O que acontece com aqueles/as que não se inseriram nas universidades ou no

Educação \& Realidade, Porto Alegre, v. 41, n. 1, p. 69-90, jan./mar. 2016. 
mercado de trabalho? Até que ponto a escola estaria levando aspirações incompatíveis com as reais oportunidades? Os desenhos de projetos de vida feitos na escola tiveram alguma inferência em sua situação concreta pós-ensino médio?

Falar em perspectivas juvenis e educação remete a uma compreensão epistemológica da realidade social contemporânea. Atualmente, vivemos em um mundo globalizado, que a cada dia se transforma, em uma velocidade extrema, para satisfação dos interesses de uma classe hegemônica comandada pela lei de mercado flexível e volátil. Compreender essa complexidade social requer reflexões para entender melhor os projetos de futuro dos jovens egressos da referida instituição.

Saviani (2011) alerta sobre a crise para a juventude contemporânea quando reconhece que o indivíduo terá de exercer sozinho sua capacidade de escolha visando adquirir meios que lhe permitam ser competitivo no mercado de trabalho. Para o autor, o que o jovem de hoje espera das oportunidades escolares já não é o acesso ao emprego, mas apenas a conquista do status de empregabilidade. A educação passa a ser entendida apenas como um investimento em capital humano individual que habilita as pessoas para as competições pelos empregos disponíveis.

O acesso a diferentes graus de escolaridade amplia as condições de empregabilidade. Porém, somente isso não garante emprego, pelo simples fato de que, na forma atual de desenvolvimento capitalista, não há empregos para todos. A ordem econômica atual assenta-se na exclusão. Portanto, boa parte daqueles/as que conseguem uma determinada formação ou atingem a idade para ingressar no mercado de trabalho fica excluída.

Na mesma direção Ramos (2011), reforça a concepção anterior ao afirmar que os valores difundidos pelo ideário neoliberal são baseados na teoria do capital humano e na pedagogia das competências, cujo princípio é a adaptabilidade do indivíduo às mudanças, às incertezas e flexibilidade do capital. Isso inclui também estar preparado para o desemprego, o subemprego, o trabalho autônomo e informal.

Nessas condições, as escolas tornam-se espaços para reprodução das desigualdades sociais e culturais, porque o conhecimento repassado para os jovens é organizado para satisfazer aos interesses de um grupo hegemônico. Os saberes desse grupo permeiam as práticas e falas escolares e conseguem imprimir saberes universais a contextos particulares que envolvem conceitos de submissão, autoridade, competências individuais, regras e convenções na intenção de produzir jovens eficientes e competitivos.

Aparentemente há coerência na relação entre melhor qualificação e maior empregabilidade. Contudo, é incoerente desarticular as políticas de emprego e renda das políticas sociais. Os discursos neoliberais 
propagam a ideia de que os jovens estão desempregados por falta de qualificação, ocultando a face perversa do mercado.

Ao analisar essa relação, Oliveira (2003) percebe a complexidade da situação e reconhece que o processo de desenvolvimento do sistema vigente aponta para a redução da capacidade de absorção da mão de obra disponível. Continuar insistindo nesse discurso de que apenas a qualificação profissional representa a única saída para os jovens menos favorecidos implica ocultar que as impossibilidades de inserção no mercado de trabalho não decorrem da incapacidade dos mesmos, mas são consequências de um modelo de sistema que tem como base o aumento da exclusão.

O mais preocupante nessa realidade é o que se passa a configurar como expectativa de futuro para essa parcela significativa da população. Tal preocupação tem como reflexo o questionamento da função da escola contemporânea, seja ela profissional ou não. Assim, vários são os autores que vêm tratar dessa questão, dentre eles Canário, Arce, Leccardi, Saviani, Frigotto, Dayrell, Carrano, Pais, Sales.

A democratização do ensino e das escolas conjugada com a crise no mundo do trabalho, de acordo com Canário (2008), tende a aumentar a discrepância entre o aumento de diplomas escolares e a diminuição de empregos correspondentes. Em sua compreensão, esse fato origina uma desvalorização dos diplomas escolares. Esse fenômeno é preocupante e relevante para reflexões:

\begin{abstract}
[...] o que acontece é que a escola tem vindo a funcionar como um fator de contenção artificial do desemprego, 'parque de estacionamento' de potenciais desempregados. Contudo, a percepção que alguns jovens têm de certificação escolar é a de 'cheques pré-datados', sem valor no presente e, possivelmente, sem valor no futuro (Pais, 2006, p. 323).
\end{abstract}

O efeito perverso dessa contenção é bem claro: aumenta-se o nível de qualificação e de certificação e, paralelamente, diminui-se o número de emprego. Diante das dificuldades que enfrentam, alguns permanecem dependentes da família ou descobrem meios para de alguma forma sobreviverem.

Nessa discussão, Arce (2009) questiona a perda de força da educação no imaginário juvenil como elemento de mobilidade social, diante de uma sociedade que apresenta um esgotamento no mundo do trabalho. O autor também aborda como questão central as concepções homogeneizantes sobre a juventude que constroem esquemas interpretativos supostamente universais e não consideram as heterogeneidades internas ou mesmo as profundas desigualdades sociais. Em sua compreensão, assim como na dos demais autores citados, a condição juvenil é polissêmica e representa uma construção social. 
Segundo Dayrell e Carrano (2003), uma das maneiras mais conhecidas de perceber os jovens é a que enxerga a juventude em sua condição de transitoriedade, onde o jovem é um vir a ser, tendo na projeção do futuro a confirmação do sentido das suas ações no presente. Nesse sentido, a juventude é vista como algo que ainda não chegou a ser, negando o presente vivido.

Em pesquisas sobre as perspectivas de futuro dos jovens, Sales $(2001 ; 2011)$ apresenta suas inquietações acerca das resiliências que estes encontram diante da sociedade contemporânea. Diante da realidade, a autora faz uma analogia da vida dos/as jovens com a vida circense, ao questionar os desafios enfrentados pelos/as jovens ao buscarem sua inserção num futuro marcado por incertezas e riscos, expressando assim suas angústias e reflexões:

A perspectiva de futuro é conseguir chegar com vida do outro lado da corda bamba, é vencer os riscos dos saltos mortais que precisa dar para sobreviver. É, também, representar papéis tendo que se fantasiar e fazer cambalhotas para ser aceito com sorrisos. É, ainda, ser engolido pelos animais que não conseguiu domar. Diante desse quadro circense, o real e o imaginário se confundem, e, como diz Foucault, o que fazer de si mesmo? (Sales, 2001, p. 1).

São essas questões que nos mobilizaram a desenvolver esta pesquisa, a buscar conhecer os percursos traçados pelos jovens egressos diante da realidade contemporânea. Leccardi (2005), ao definir a noção de futuro como espaço para a construção de um projeto de vida e, ao mesmo tempo, para a definição de si, pois acredita que ao projetar o que se fará no futuro, projeta-se também quem se será, questiona seu significado diante de uma realidade dinâmica e imediatista.

Dessa forma, comungamos com essas concepções ao trazer para a pesquisa a compreensão da conceptualização que encara as diferentes formas de juventudes - expressas no plural -, heterogêneas; essa diversidade se materializa nas diversas condições de cada sociedade e/ou grupos (etnias, religiões), na riqueza e complexidade de gêneros, bem como nos diversos espaços geográficos percorridos pelos jovens. É dentro dessa ótica que trabalhamos ao longo da pesquisa, compreendendo a complexidade e a riqueza sociológica a que a noção de juventude está atrelada e dialogando com autores que comungam com essa abordagem construtiva histórica e social da juventude.

Dentro dessa compreensão buscamos uma metodologia que melhor se aproximasse do objeto de pesquisa, como também do nosso próprio jeito de ver e sentir o mundo e as pessoas. Foi assim que optamos por trabalhar com a abordagem da Pesquisa Qualitativa, pois esta, de acordo com Bogdan e Biklen (1994), permitia-nos questionar os sujeitos da investigação com o intuito de perceber e compreender aquilo que eles experimentavam, o modo como eles interpretavam e sentiam as suas experiências fora dos muros escolares, bem como o modo como 
eles estruturavam o mundo social em que viviam, ou seja, caminhamos com passos firmes em direção a uma perspectiva que se preocupasse e valorizasse os sentimentos, as falas, as experiências e emoções dos sujeitos envolvidos.

Dessa forma, tivemos o cuidado de escolher uma abordagem investigativa que dialogasse com os sujeitos envolvidos da pesquisa, no caso, jovens egressos de uma escola profissional.

As entrevistas narrativas foram realizadas com jovens que concluíram seus estudos na escola e fazem parte da amostra mais abrangente do estudo. Através das entrevistas narrativas, fomos obtendo informações biográficas e sociais dos envolvidos e simultaneamente percebendo e refletindo a prática pedagógica escolar. Foi também a partir delas que conseguimos enxergar, no sentido amplo da palavra, os jovens por um ângulo mais singular, além de capturarmos peculiaridades de suas trajetórias e o sentido que eles/elas atribuem às suas histórias de vida nas circunstâncias em que vivem.

O método, assim, abria a perspectiva de um caminhar diferente, pois partia da premissa de que era preciso considerar nas práticas socioeducativas o conjunto de saberes historicamente produzidos, inclusive aquele saber gerado pelos sujeitos sociais da realidade cotidiana em que viviam. Dessa forma, percebíamos que trazendo o passado para o presente, por meio da contação de histórias, poderíamos fazer com que os jovens, através de seus relatos, refletissem sua realidade atual e, quiçá, projetassem seus futuros.

Analisamos as entrevistas de quatro adolescentes. É preciso ainda explicar que o anonimato dos jovens foi preservado e respeitado, portanto, para identificá-los, usamos nomes fictícios para cada entrevistado.

Os/as jovens entrevistados/as contaram suas experiências de vida através de um exercício de relembrar, ou seja, lembrar de novo parte de algumas de suas memórias - as que quiseram contar, outras foram ocultadas, outras esquecidas. Compreendendo que a memória é seletiva e afetiva, não constituindo um aspecto neutro por parte de quem a usa, buscamos no momento das entrevistas criar um ambiente propício de confiança e respeito. O exercício também possibilitou aos jovens construírem suas próprias teorias sobre os percursos de suas vidas, contrastando vitórias e fracassos, tristezas e alegrias, conquistas e frustrações, medos e incertezas.

\section{Futuro: incertezas, medos e inconstâncias}

João tem 19 anos e é o mais novo de sua família, mora com a mãe e mais três irmãs e não conheceu seu pai biológico. Para ele, a mãe é sua referência maior, sente a necessidade de ajudá-la e, para isso, buscou através dos estudos melhorar a vida da família. 
João era um aluno com sérios problemas de aprendizagem durante seus estudos na escola, desde o primeiro ano ele demonstrava dificuldades básicas na leitura, na escrita, bem como nos desafios lógicos matemáticos. Formou-se no curso de técnico de Enfermagem. Hoje João trabalha no Hospital Geral de Fortaleza como técnico de enfermagem e continua estudando para concurso.

Assim como para uma grande parcela das crianças dos bairros periféricos da cidade, João teve que antecipar o início da vida adulta para antes dos seus 15 anos, na medida em que precisou tomar decisões inerentes ao mundo do trabalho. Conforme afirma Carrano (2009), para os jovens das classes populares, as responsabilidades da vida adulta, especialmente a pressão para a entrada no mercado de trabalho, chegam enquanto estes ainda estão experimentando a juventude ou mesmo a infância, como foi o caso de João.

Eu estava no final do ano aí surgiu essa proposta das escolas profissionalizantes, que ainda estavam sendo criadas pelo governo. Aí eu pensei: será que eu vou me dar bem? Será que vai ser fácil pra mim? Será que vai ser uma boa? Pra mim aprender mais, pra mim me profissionalizar, aprender um curso profissionalizante? Aí eu resolvi fazer a prova aqui nessa escola e tinha que escolher entre três cursos pra mim fazer a opção, aí tinha Informática, Turismo e Enfermagem, eu não tinha nenhum curso específico na minha cabeça, não tinha ideia do que eu ia fazer, aí eu optei pela Enfermagem, não sei como eu optei, mas eu acabei escolhendo a Enfermagem (Entrevista com João, 01 dez. 2013).

Perante estruturas sociais cada vez mais fluidas e aleatórias, João sente o seu futuro marcado por incertezas, medos e inconstâncias. São muitos os medos nessa fase da sua vida: medo de estudar e não se dar bem, medo de aprender uma profissão, medo de não conseguir aprender, medo de fracassar. Seus contextos social e emocional lhes servem como referência para tomar suas decisões. As dúvidas e anseios ganham ascendência e se avolumam, e o jovem faz opções de futuro sem um amadurecimento adequado, assim como num jogo, numa tentativa de acerto e erro, sem saber por que, escolhe o curso de Técnico de Enfermagem para ingresso na escola profissional.

A história de vida de João confirma os estudos de Pochmann (2004) quando este afirma que os jovens filhos de pobres no país encontram-se praticamente condenados ao trabalho precário como uma das poucas condições de mobilidade social. Porém, ao ingressarem muito cedo no mercado de trabalho, o fazem com baixa escolaridade, ocupando as vagas de menor remuneração. O contrário parece ocorrer com os jovens filhos de pais de classes média e alta, os quais, em geral, possuem condições de financiar a inatividade, prolongando a escolaridade e postergando o ingresso no mercado de trabalho.

A experiência de vida de João reflete as trajetórias descontínuas que a juventude vive hoje no país. A vivência precária do trabalho e do emprego envolve modalidades múltiplas de luta pela sobrevivência que 
compreendem trabalhos precários, temporários, ocultos, ilegais, domésticos, formas variadas de ganhar a vida a que Pais (2006) se refere com as sugestivas expressões ganchos, tachos e biscates.

Gancho e biscate são termos que se usam em sentido equivalente, representam o exercício de atividades profissionais de caráter precário, secundário. Assim, o jovem se vê numa encruzilhada, em uma situação inesperada, a indeterminação: à medida que se preparava para uma profissão, Técnico de Enfermagem, ter que trabalhar como biscate em uma lanchonete. O projeto de futuro imaginado e sonhado é ameaçado diante da realidade, o jovem procura se adaptar às circunstâncias mutáveis que fazem mudar o curso de sua vida.

As aulas acabaram, e eu tive que escolher: e agora, o que é que eu vou fazer da minha vida? Não tinha terminado ainda o curso, estava no estágio ainda, aí eu tive que começar a trabalhar, porque eu precisei, questão de família, precisei trabalhar. Aí eu fiquei trabalhando de tarde e fazendo o estágio de manhã e foi muito pesado pra mim, porque eu tive que trabalhar todo dia, eu trabalhava no shopping de atendente de lanchonete, no shopping Del Paseo, e eu trabalhava nesse shopping e ainda continuava fazendo o estágio, nunca cheguei a desistir. Aí tinha tempo que eu faltava no trabalho, mas continuava fazendo o estágio, aí eu tinha sempre que querer continuar fazendo o curso pra eu sair com o meu certificado e com o meu aprendizado completo, aí eu continuei por três meses nesse trabalho e, quando eu terminei o estágio, eu deixei o trabalho e fiquei sem emprego (Entrevista com João, 01 dez. 2013).

Uma particularidade de muitos jovens atuais é a de viverem um tempo de instabilidade e de incertezas, de tensão entre o presente e o futuro. A ideia moderna de futuro com a qual nos acostumamos - uma dimensão separada do presente e distinta do passado, controlável e planificável - nasce em uma época relativamente recente, entre os séculos XVII e XVIII, configurando-se até meados do século XX, com a afirmação da concepção linear do tempo na razão cultural europeia. Assim, em sociedades ocidentais, o controle do futuro foi dado como evidente, certo e irreversível (Leccardi, 2005).

Com a modernidade contemporânea, governada por processos de intensificação da globalização, dos mercados livres, do individualismo institucionalizado, do consumismo compulsório, surgem os riscos globais: crise ambiental, terrorismo internacional, ameaças econômicas tipo planetárias, novas modalidades de emprego e subemprego, novas formas de relação e contratos de trabalho. Neste novo cenário, há cada vez menos espaços para dimensões como segurança, controle, certeza e planejamento de futuro. Leccardi (2005), Pais (2003; 2006) e Arce (2009), entre outros autores, vêm nos alertando sobre essa nova perspectiva que a dimensão do tempo futuro vem sofrendo nos últimos anos. A ideia de futuro é, portanto, não determinada, não linear e simultaneamente atravessada por sentimentos confusos de instabilidade, angústia e impotência. 
Como explicar para João que esses seus sentimentos de insegurança, de labirintos de vida, como se não soubesse que caminho seguir para encontrar uma porta de saída, eram próprios da realidade histórica na qual ele se encontrava imerso? Na sua compreensão, as fases de sua vida eram lineares, contínuas e consistiam em: estudar e preparar-se profissionalmente por meio da formação escolar; depois o exercício de um trabalho bem remunerado, fonte central de identidade e signo indiscutível da idade adulta; a constituição de uma família; e, por fim, a aposentadoria. Hoje, essa trajetória biográfica, capaz de garantir um percurso previsível para o ingresso na vida adulta, constitui não mais a regra geral, mas, sim, a exceção.

A formação do indivíduo não ocorre no abstrato, mas, dentro de uma materialidade concreta. Compreendemos também que, para os jovens das classes populares, é fundamental o processo educativo servir, de alguma forma, para os mesmos poderem, no futuro, competir em melhores condições por uma vaga no mercado de trabalho. Entretanto, é no mínimo pouco crítico acreditar que o processo de escolarização, por si só possa garantir a inserção futura no mercado de trabalho (Oliveira, 2003).

Assim, compartilhamos com as ideias do referido autor quando afirma que a relação escola e trabalho não pode se estabelecer subordinando a escola ao capital. Ou seja, pensar a escola como tendo a obrigação de somente preparar para o mercado de trabalho leva, impreterivelmente, a repensar a qualidade e função da escola, para que esta não se reduza a uma ótica exclusivamente mercantil. A educação não pode ser entendida apenas como um instrumento de mobilidade social, mas, preponderantemente, como uma possibilidade de enriquecimento pessoal. E, mesmo quando a formação é dirigida à inserção profissional, não há garantia de que esta ocorra.

Pais (2006) reforça essa concepção quando afirma que a formação profissional é indispensável ao bom desempenho de uma atividade profissional, reconhecendo a necessidade urgente de maior e melhor investimento, por parte das políticas públicas, na formação profissional dos jovens. Porém, o problema surge quando há um o discurso oficial de que, ao expandir a formação profissional aos jovens, soluciona-se o problema do desemprego juvenil. Sabe-se, hoje, que essa equação está longe de ser verdadeira.

Durante séculos da humanidade as aprendizagens foram realizadas em continuidade à experiência de vida e por imersão na própria realidade social do indivíduo. Hoje, a escola - invenção histórica e recente, responsável por fabricar o ser social - instituiu um espaço e um tempo distintos, destinados à aprendizagem. A separação da realidade social produziu um efeito de fechamento e isolamento da escola sobre si mesma, cujos inconvenientes estão bem patentes no desejo recorrente manifesto de ligar a escola à vida. Subestimar e negar as experiências

78 Educação \& Realidade, Porto Alegre, v. 41, n. 1, p. 69-90, jan./mar. 2016. 
dos jovens tem-se traduzido em um problema grave para a sociedade, marcando negativamente as relações entre seus atores (Canário, 2008).

Após a conclusão do curso, João ficou desempregado e também não conseguiu entrar para a universidade, apesar de continuar estudando em cursinhos preparatórios para o ENEM. Até que, no final do ano de 2012, surge uma oportunidade de trabalhar no Hospital Geral de Fortaleza no cargo de técnico de enfermagem. Na realidade, o que João não sabia era que o hospital, como toda empresa capitalista com o intuito de redução de custos, mantinha uma parceria com uma cooperativa para contratar mão de obra mais barata. $\mathrm{O}$ sistema de cooperativa de trabalho mantém um vínculo de livre associação do indivíduo sem direitos contratuais, sem carteira assinada, sem férias nem décimo terceiro, o cooperado é livre para permanecer ou não na cooperativa e vender sua mão de obra e serviços. Após a contratação pela cooperativa, o jovem foi encaminhado para trabalhar no hospital.

O trabalho no hospital requeria do jovem uma dedicação exclusiva e exaustiva de tempo e atenção e também representava a oportunidade de pôr em prática o que ele havia aprendido no curso técnico de Enfermagem. A responsabilidade avoluma-se quando o jovem se vê diante da realidade de cuidar de seres humanos reais, de pessoas debilitadas e fragilizadas física e emocionalmente.

É difícil porque lá eu trabalho muito, a carga horária é de 12 horas por dia, quando eu trabalho de dia, eu entro de sete da manhã e saio sete da noite, às vezes eu trabalho à noite, sete da noite e saio sete da manhã, aí tem vez que eu trabalho 24 horas, aí fica muito pesado, aí questão de estudo... você tem que saber, tem que ser forte, porque lá tem gente que, a maioria lá faz faculdade, é esforçado, trabalha lá, chega em casa, vai estudar, no outro dia faz prova... Mas, assim o... a equipe lá quer ajudar a pessoa... A chefe lá, tipo, lhe ajuda, deixa você fazer troca... é... concilia bem seu horário pra que você faça seus estudos, e quem faz faculdade tem o direito de sair um pouco mais cedo pra ir pra faculdade à noite, o horário lá é sete horas pra sair, mas se der pra sair às seis sai, faz tudo pra que a pessoa cresça, eles não pensam assim que a pessoa vai ser limitada, eles pensam sempre no crescimento profissional (Entrevista com João, 01 dez. 2013).

As possibilidades e limites de uma formação profissional de qualidade, voltada menos para os interesses estritos do mercado e mais para uma formação de caráter emancipatória dirigida aos jovens, oportuniza a ampliação e valorização do saber do jovem.

Frequentemente os relatos de vida são construções de realidades passadas, ausências apenas presentes na memória. Aliás, a memória expressa-se muitas vezes através de silêncios, de lacunas, de não ditos. João não diz algumas coisas, silencia outras, mas o que ele não expressa em seus relatos é percebido nos silêncios e nos não ditos. O jovem deixa entre linhas, lacunas e silêncios a sua insegurança com relação a sua profissão; fala cortando as palavras, como se estivesse com receio de falar que aquela não era a profissão almejada, estava ali por contingências 
da vida, por necessidades financeiras. Afinal, entre o assistente de lanchonete do shopping Del Paseo e o técnico de Enfermagem do Hospital Geral de Fortaleza, ele opta pelo último.

O jovem permanece trabalhando no hospital com uma jornada de trabalho exaustiva, porém não abre mão de acreditar em tempos melhores. Tem como perspectiva para o futuro fazer uma faculdade de Fisioterapia ou Engenharia para melhorar de vida e, quem sabe, sair dessa profissão.

\section{Escola como Trampolim para Vida}

Maria tem 19 anos, na época de aluna na escola profissional, apresentou sérios problemas tanto de aprendizagem dos conteúdos como de relacionamento com os colegas. A jovem concluiu o curso técnico de Guia de Turismo e atualmente trabalha como recepcionista de uma pousada. Maria sonha um dia ter seu próprio negócio.

Em Fortaleza, como nas demais cidades do país, há centenas de crianças e jovens que convivem com o problema do alcoolismo na família, ocasionando a violência doméstica, maus-tratos e traumas profundos entre seus membros.

O alcoolismo do pai é motivo de grandes desavenças na família, e Maria sofre demasiadamente com as agressões e brigas domésticas. Esse aspecto da vida de Maria a acompanha da infância até os dias de hoje, representando algo que mexe com suas estruturas emocionais, sociais e cognitivas.

O sentido de existência cotidiana de Maria é roubado pela sua realidade. Sentindo-se impossibilitada de transcender o determinismo herdado pela vida, ela desiste algumas vezes de lutar e de sonhar. A jovem, porém, não compreendia que tanto os sonhos como a esperança brotam da intimidade interior do ser, e não da sua exterioridade, por isso buscava preencher seus vazios existenciais nas coisas externas. Durante seu relato, ela fala com serenidade das vezes que tentou suicídio e das vezes que fugiu de casa. Ambas tentativas na busca incansável de fugir de seus problemas, ambas também fracassadas como experiência de vida, porém marcantes em seus relatos. Nessa época de sua vida, quando ainda frequentava o Ensino Fundamental, as coisas estavam confusas, opacas, e as emoções embaralhavam-se de forma difusa. A jovem, envolvida emocionalmente com os problemas familiares, não conseguia manter um relacionamento com os amigos, e seus problemas na escola avolumaram-se.

Para a jovem, a escola se mostrava distante de seus interesses e necessidades, reduzida a um cotidiano enfadonho, tornando-se cada vez mais uma obrigação, tendo em vista a necessidade de um diploma. Dayrell (2007) reflete sobre em que medida a escola faz a juventude, privilegia as tensões e ambiguidades vivenciadas pelo jovem, levantando o 
questionamento do papel da escola, uma vez que ao constituir o jovem como aluno, como estudante no cotidiano escolar, não respeita a sua condição juvenil e sua realidade individual, gerando uma tensão nessa dupla condição - ser jovem e ser aluno - que, muitas vezes, torna-se difícil de ser articulada.

O debate sobre a escola tem vindo estruturar-se em torno de um conjunto de conceitos como qualidade, avaliação e inovação, os quais configuram um diagnóstico sobre os males da escola centrados na questão da eficácia. Para Canário (2008), o problema central hoje da escola é de déficit de legitimidade social, pois faz o contrário do que diz, reproduz e acentua desigualdades e fabrica exclusão relativa, o que condiciona o principal requisito para que a escola seja eficaz: a construção de um sentido positivo para o trabalho que é realizado.

A vinda para a escola profissional foi para ela uma oportunidade de sair de casa, de ausentar-se do clima difícil que a família passava com as bebidas e brigas do pai. Ela não compreendia muito bem o significado nem a proposta da escola, apenas queria um local e espaço para afugentar-se dos seus tormentos. A aluna trazia consigo suas marcas, suas cicatrizes da vida cotidiana, e, como tal, estas não poderiam deixar de interferir no seu dia a dia escolar. Seus problemas afetavam tanto a aprendizagem dos conteúdos escolares como as relações com os colegas. Maria não conseguia as médias necessárias para passar de ano, chegando a ficar em dependência em algumas matérias. Porém, a proposta pedagógica da escola, com um acompanhamento mais próximo do/a aluno/a, com o tempo integral para conhecer melhor as necessidades dos/das jovens e com atividades curriculares voltadas para trabalhar o emocional, permitiu-lhe uma melhor adaptação ao sistema.

A transitoriedade e a aleatoriedade pautam os percursos profissionais de muitos jovens, como os de Maria. Para ela, suas experiências anteriores não representam um trabalho, os conceitos de emprego e desemprego se manifestam desajustados em relação à realidade vivida por ela. São mais sugestivas as expressões correntes usadas em seu cotidiano, como biscates e bico, para retratar os seus curtos e repetidos ensaios pelo mundo do trabalho.

Maria terminou o curso com dificuldades e conseguiu mudar um pouco suas perspectivas de vida e de futuro. Ao concluir o curso, a jovem não conseguiu ingressar de imediato no mercado de trabalho, tampouco na universidade; foi preciso um tempo maior para isso. Hoje ela está trabalhando em uma pousada próxima à cidade como recepcionista e está feliz com o que faz. Agora, trabalhando com carteira assinada, optou novamente por morar sozinha, mantendo-se com o salário que recebe e ainda ajudando os pais quando necessário.

O relato de vida de Maria sugere que situações desfavoráveis da infância e da adolescência nem sempre se traduzem numa trajetória de vida marcada pelo insucesso. Como relatado pela própria jovem, sua 
infância foi marcada negativamente pela violência familiar e pelo insucesso escolar imputável também às faltas contínuas dos professores na escola regular. Para Maria, foi seu ingresso na escola profissional que se constituiu num trampolim para dar o salto em sua vida. E isso só foi possível porque a jovem percebeu na escola uma possibilidade palpável de mudança, ali ela encontrou objetivos concretos de vida: estudar para ter uma profissão; sair definitivamente da dependência do pai através do trabalho; morar sozinha, sonho alimentado desde pequena; ajudar sua mãe.

\section{Ensino Médio: que caminho seguir?}

Thiago tem 19 anos e mora com os pais e um irmão mais novo. Thiago, na escola, era considerado aluno inquieto, aquele que vivia na coordenação. Suas notas eram medianas, conseguia passar de ano com dificuldades.

Thiago concluiu o curso de técnico de Guia de Turismo e atualmente encontra-se desempregado, buscando qualificação.

Desde criança sempre gostou de fazer amizades e buscava a companhia dos amigos em todos os momentos. Em verdade, essa é uma característica que acompanhará o jovem durante seu percurso de vida, seus amigos sempre influenciaram no seu modo de vida.

Thiago questiona a partir do seu ponto de vista a perspectiva institucional da escola pública contemporânea, principalmente a escola que frequentava antes da EEEPPP.

Canário (2008) questiona o futuro da escola, para ele esta apresenta três questões centrais que necessitam ser pensadas: a escola hoje é obsoleta, pois é baseada em conteúdos cumulativos e revelados; a escola padece de um déficit de sentidos para os que nela atuam, tanto professores quanto alunos; e é marcada por um déficit de legitimidade social, pois a escola faz o contrário do que diz. Em sua compreensão, não é possível prever o futuro da escola, mas é possível e necessário problematizá-lo. Nesse sentido, professores e alunos são prisioneiros dos problemas e constrangimentos que decorrem do déficit de sentido das situações escolares.

O vazio de sentido que o jovem vivenciou naquela instituição o levou a outra experiência bastante complexa para a juventude atual: o contato com o mundo das drogas, da criminalidade e da marginalidade. Embora a escola possa e deva ajudar na prevenção da delinquência e da marginalidade, também em alguns casos ela pode colaborar na produção da delinquência, através de práticas que fomentam ou acentuam a frustração dos alunos, o seu desinteresse, a sua apatia e a sua rebeldia (Pais, 2006).

Thiago consegue ingressar na EEEPPP mais por desejo de sua mãe que seu, sem compreender muito bem a proposta pedagógica da escola 
e, como ainda estava com a cabeça desviada, não conseguia entender a dimensão que aquela escola poderia trazer para sua vida futura, uma vez que trabalhava com a formação profissional. Portanto, sem refletir muito sobre o assunto, optou por fazer o curso de Técnico de Guia de Turismo influenciado mais uma vez pelos amigos, mesmo não gostando da área.

Thiago, na maioria das vezes em sua vida, deixa-se influenciar pelos amigos e, assim como na escola regular, terra de ninguém, vai fazendo escolhas, tomando rumos na sua vida. As condições na escola foram mais favoráveis para ele, pois aos poucos o jovem foi se afastando das companhias dos amigos com quem convivia nas pichações, nas paradas para roubos, nas rodas para dividir a droga. Em busca de um futuro vindouro, abandona um presente real.

Leccardi (2005) aborda o mecanismo denominado diferimento das recompensas - a repressão dos impulsos hedonísticos, a determinação de adiar para um tempo vindouro a satisfação que o presente pode garantir - como processo fundamental nos processos modernos de socialização. É em virtude da capacidade de viver o presente em função do futuro que o processo de transição pode alcançar um resultado satisfatório. Assim, o presente não é apenas uma ponte entre o passado e o futuro, mas também uma dimensão que prepara o futuro (Leccardi, 2005).

As perspectivas lineares de progresso e de desenvolvimento, consideradas como aspectos definidores da ideia de futuro da modernidade, perderam parte relevante de sua força, deixando grandes núcleos populacionais mutilados em suas possibilidades de ampliarem seu horizonte de promessas (Arce, 1999). É nesse contexto que Pais (2006) afirma que para muitos jovens, especialmente para os mais desfavorecidos, a vida é uma loteria, um jogo onde os riscos estão fora de controle e a segurança é uma questão de sorte.

É necessário questionar em que medida a relação entre projeto de futuro, tempo biográfico e identidade, aspectos inerentes do diferimento das recompensas, pode ainda ser considerada válida em uma sociedade contemporânea dominada por incerteza e contingências. Thiago foi preparado pela escola para estudar para o mercado de trabalho, tem a convicção que essa formação vai fazer toda a diferença no futuro.

No final do curso, Thiago teve suas certezas mais uma vez abaladas; foi quando confirmou que o curso de Guia de Turismo realmente não tinha nada a ver com ele. No período do estágio, o aluno teve contato com as empresas de turismo e precisava por em prática um pouco da teoria aprendida na escola. Nessa fase ele sentiu dificuldades em executar as atividades específicas do curso.

Eu pensei, o curso não era o que eu queria e eu fiquei sem caminho pra seguir, sem, sem fazer nada, procurei emprego, recebi vários nãos de muitas empresas e assim foi, foi passando o tempo, eu fui descuidando... 
e eu passei um ano sem praticamente fazer nada. Foi um período que eu procurei todo tipo de emprego e recebi muitos nãos, talvez isso tenha até me ajudado, esses nãos, pra ver que eu tenho que me capacitar pra conseguir emprego e eu fiquei meio que sem caminho a seguir quando, quando terminei o curso, porque não era o que eu queria e agora vou fazer o quê? Vou atrás de emprego, só recebo não, eu fiquei sem caminho pra seguir... (Entrevista com Thiago, 04 dez. 2013).

O jovem conclui o curso e sente-se perdido, sem caminho para seguir, não se identificou com o curso, não ingressou na universidade. Então, sem saber muito bem que percurso seguir, Thiago, como num labirinto onde se busca vários caminhos para encontrar uma saída, sai em busca de todo tipo de emprego, percorre muitas empresas sem ser de sua área e recebe vários nãos. Essa situação perdurou por mais de um ano, sem emprego e sem faculdade. Como tantos jovens, Thiago não sabe que caminho seguir, “[...] pois o futuro é uma referência opaca que solapa a ausência de opções frente a seus problemas fundamentais” (Arce, 2009, p. 20. Tradução livre).

$\mathrm{O}$ que aconteceu com os projetos traçados por Thiago durante seu curso técnico? Para onde foram suas expectativas, suas aspirações? Com o diploma na mão, não consegue alcançar os trajetos idealizados, as portas que se abrem para o jovem conduzem-lhe a um vazio existencial.

Quando Thiago conseguiu emprego em uma grande indústria de produção de calçados na região da Barra do Ceará, o serviço não tinha nenhuma relação com sua formação escolar, tampouco com a área que Thiago gostava, que é a internet. Com o salário que recebia na indústria, começou a pagar um curso técnico de Informática.

Quando questionado sobre suas perspectivas de futuro, Thiago revela que pretende estudar bastante, fazer faculdade e depois se especializar mais para poder ter um bom emprego. Essa ideia da especialização, qualificação, como determinante para conseguir um bom emprego ainda é bastante apresentada aos jovens pela mídia, pelos políticos, pela família e pela escola, como se apenas o esforço individual fosse capaz de inseri-lo no mercado de trabalho. A fala do jovem reafirma como esse discurso é assimilado e reproduzido pelo próprio jovem.

Hoje eu vejo que o mercado tem bastante a lhe oferecer se você tiver bem capacitado, bem graduado, tiver uma boa instrução, porque, como eu costumo dizer, não, não falta emprego, o que tá faltando é profissionais capacitados pra trabalhar, e isso eu vejo como estímulo pra mim estudar também, me formar, e isso vai acabar... O mercado em si acaba lhe forçando, lhe forçando a estudar pra ter uma graduação melhor, uma formação melhor, que é o que vai ser o diferencial das outras concorrentes a uma vaga de trabalho, é a sua qualificação, porque vaga tem bastante nas empresas, em concursos, que é preciso estudar, tudo sempre tem bastante vaga, o que vai, o que vai lhe fazer diferencial de você e o seu concorrente é a sua qualificação e o seu caráter (Entrevista com Thiago, 04 dez. 2013). 
Segundo Ramos (2011), a ideologia embasada na teoria do capital humano foi difundida através da pedagogia das competências, cujo princípio é a adaptabilidade individual do sujeito às mudanças socioeconômicas do capitalismo, o que inclui também estar preparado para o desemprego, o subemprego ou o trabalho autônomo. Essa é a nova ética que subjaz à ideologia da empregabilidade e que, em linhas gerais, significa um esforço por parte do indivíduo para buscar as oportunidades que a sociedade ou o mercado oferecem.

Propaga-se que a chance de arranjar um emprego será aumentada pelo simples fato de as pessoas disporem de um maior capital cultural ou de uma melhor qualificação; oculta-se o fato de que a subordinação de nossa economia não abre possibilidades de geração de novos postos de trabalho (Oliveira, 2003).

Thiago desiste do emprego que o explora. Sem trabalho, não perde apenas o emprego, mas também a oportunidade de aquisição dos bens de consumo cotidianos. Voltar a estudar e depender financeiramente dos pais são sinais de retrocesso na linearidade de sua vida.

É porque vivem em estruturas sociais labirínticas que os jovens contemporâneos se envolvem em trajetórias ioiô, pois perante estruturas cada vez mais fluidas os jovens sentem suas vidas marcadas por inconstâncias, descontinuidades, reversibilidades: saem das casas dos pais para qualquer dia voltarem; abandonam os estudos para os retomarem mais tarde; encontram um emprego e em qualquer momento se veem sem ele (Pais, 2006). Por isso os sociólogos da juventude falam em trajetórias alongadas, frustradas, adiadas. Os percursos de passagem para a vida adulta não são apenas incertos. São percursos obscuros, sinuosos, com obstáculos e reversíveis. De fato, assiste-se, na sociedade contemporânea, a um prolongamento da condição juvenil onde os caminhos escolares são mais longos, há um retardamento da inserção no mercado de trabalho formal, o acesso à casa própria é difícil, o casamento é mais tardio.

Thiago volta para os bancos escolares, faz o vestibular em uma faculdade particular da capital e entra para o curso de Análise de Sistemas na área da Informática. Com a ajuda dos pais e uma bolsa de estudos de $50 \%$ do programa federal Educa mais Brasil, o jovem alonga sua escolaridade na esperança de um futuro melhor.

\section{Driblando seus Próprios Percursos}

Pedro é um jovem de 19 anos de idade e mora com os pais e uma irmã mais velha. Pedro era o aluno calmo, estudioso, sempre conseguia estar entre os melhores resultados da escola.

Pedro terminou o curso técnico de Informática e foi convidado pela empresa em que estava estagiando para permanecer em seu quadro como funcionário com carteira assinada e lá se encontra até hoje. Pedro sonha lançar-se no meio do mundo.

Educação \& Realidade, Porto Alegre, v. 41, n. 1, p. 69-90, jan./mar. 2016. 
Discutir as trajetórias de vida dos jovens da periferia requer identificá-las a partir de sua própria realidade. Na casa de Pedro, como na de tantas famílias pobres, o trabalho infantil significa afastar os filhos da marginalidade, além de ser fonte de renda complementar à dos adultos. Como toda criança que necessita desenvolver determinados trabalhos para complementar a renda familiar, Pedro rejeitava vender dindim nas praias das Goiabeiras; aborrecia-se com a mãe, que o obrigava ao serviço; queria brincar com os colegas, jogar bola, tomar banho de mar, vivenciar as coisas boas da infância. O seu tempo social imprime marcas diferentes em seu corpo de criança.

Os jovens entrevistados não habitam apenas nos seus relatos individuais, eles também transportam consigo marcas coletivas que incluem as famílias, os amigos, o bairro. Questionado se já havia perdido algum amigo para as drogas, Pedro responde:

Perdi, sim. Inclusive alguns que nem se envolveram, que tava lá no canto dele, que levou por alguém que não deveria. Morreu, foi morto por coisa que ele não tinha feito, ele realmente não tinha feito, entende? Ele era como eu, mas, pagou por alguém que tinha feito, é esse tipo que... poxa... se minha mãe não tivesse feito isso? Se eu tivesse ficado em casa? Aí eu não sei se eu estaria realmente vivo (Entrevista com Pedro, 28 abr. 2014).

Segundo Furter (1974), a sociedade capitalista deixa uma pequena margem de liberdade individual em que alguns indivíduos tentarão encontrar uma solução para seus problemas existenciais. Pedro encontrou essa pequena brecha autorizada pelo capitalismo. É nessa brecha que luta pela liberdade de ser mais e vai encontrando espaços para sobreviver.

A família cumpre um papel relevante como elemento socializador e regulador de condutas. Em termos gerais, os jovens têm maior confiança em sua mãe; para eles, a mãe tem representado a figura de maior relevância em sua formação, a figura mais centrada e equilibrada do núcleo familiar. Esse dado é percebido nos discursos dos sujeitos desta pesquisa, bem como em pesquisas de autores diversos, entre os quais Sales (2011), Damasceno (2004), Arce (2009), os quais vêm constatando a importância da figura materna no desenvolvimento e na formação da personalidade dos jovens.

Em Fortaleza, como em outras cidades do país, há centenas de crianças que vivem nas praças, nos sinais e nas praias, vendendo balas, doces. Trabalham a céu aberto, à luz do dia ou na escuridão da noite, oferecendo aos transeuntes pequenas porções de doces carregados de vidas amargas.

Pedro, afastado dos centros urbanos, percorre sua infância e início da adolescência dividido entre o convívio com as drogas, os estudos e o trabalho com a mãe; sua vida foi marcada em trilhos de precariedade. Entre os jovens brasileiros, a desigualdade mais evidente é a de classe social. Esse aspecto é claramente visível na relação escola-traba- 
lho. Enquanto nos países europeus, cada vez é mais tardio o ingresso do jovem no mercado de trabalho, no Brasil a situação é praticamente inversa, de cada dez jovens, sete estão no mercado de trabalho informal e precário (Novaes, 2006).

A EEEPPP trouxe uma mudança significativa na vida do jovem, as experiências nas escolas regulares da região, assim como relatado nas entrevistas anteriores, traziam recortes de lembranças na memória de Pedro do caos em que se encontram as escolas públicas da cidade.

Apesar das dificuldades cognitivas que Pedro trazia, ele consegue superá-las e acompanhar o nível de exigência escolar e se destaca entre os demais.

A proposta pedagógica da escola, mais atenta ao diálogo com o aluno, possibilitou a muitos jovens momentos de reflexão sobre suas histórias de vida, seus projetos de futuro. A grande maioria dos/as alunos/as chega à escola sem conhecimentos mínimos necessários para prosseguirem seus estudos ou profissão. Em realidade eles e elas desconhecem os processos de inserção no mundo acadêmico, e, fato mais pujante, eles não acreditam que são capazes de ser mais.

A oferta do EMI à Educação Profissional, tendo como proposta a integração dos conteúdos mais direcionados à formação geral com aqueles que permitem compreender os princípios da técnica e da tecnologia, busca assegurar o diálogo entre a prática e a teoria, bem como motivar os jovens a contextualizarem a escola com a vida. Porém, essa integração não exclui os problemas e desafios já existentes na Educação Básica e muito menos garante a superação da conjuntura política e econômica do país. É preciso a escola estar atenta e voltada para os interesses e necessidades dos jovens. Nesse sentido, compreendemos que uma prática pedagógica significativa decorre da necessidade de uma reflexão crítica sobre o mundo do trabalho, das relações sociais que se estabelecem na produção, da precariedade de empregos, da exploração da força jovem de trabalho e da criação dos subempregos.

Pedro vence algumas barreiras, dribla o percurso do seu destino, desafia o medo e conclui o Ensino Médio Integrado à Educação Profissional, com formação em técnico de Informática. Também estimulado e orientado pela escola a prosseguir seus estudos, faz o ENEM e consegue bolsa integral para cursar uma faculdade.

Ao romper diversas barreiras de exclusão, Pedro está engendrando ações, tecendo sonhos que são capazes de gerar um novo sentido, mesmo em condições de vida completamente adversas (Sales, 2011). O estágio supervisionado realizado através da escola também oportunizou a Pedro conseguir seu primeiro emprego de carteira assinada, no qual permanece até hoje. A jornada de trabalho do jovem é extensa e dividida com os estudos à noite e nos finais de semana.

Questionado sobre seus projetos para o futuro, Pedro responde: "Eu vislumbro para o futuro um mestrado, doutorado, não pretendo fi- 
car no Brasil por muito tempo, pretendo trabalhar fora, estudar fora e, se Deus quiser, vai dar certo" (Entrevista com Pedro, 28 abr. 2014). Seu desejo de crescer pessoal e profissionalmente é movido pela curiosidade de conhecer coisas novas e ousadas, quer enfrentar desafios e lançar-se no meio do mundo para aprender sempre mais.

O desfecho da trajetória de Pedro é movido pela esperança, e, se a esperança não está desautorizada racionalmente, ela se torna um imperativo ético e conecta-se a um conjunto de práticas e procedimentos que a incorporam no seu dia a dia. Nesse sentido, qualquer que tenha sido o passado de Pedro, seu futuro é incerto e imprevisível, o que o conduz a uma abertura para atitudes à hipótese da mudança.

\section{Considerações Finais}

Interpretar relatos de vida não é apenas dar-lhe um sentido de linearidade fundamentado, mas principalmente perceber a pluralidade e riqueza do tecido de que a vida é feita, é contrapor seus significados e seus sentidos, é ler nas entrelinhas, é escutar o não dito, é acima de tudo envolvimento e emoção.

Os jovens João, Thiago e Pedro e a jovem Maria desnudaram suas dificuldades e apresentaram suas possibilidades de tornarem-se jovens no presente. Aprenderam na prática que o mercado de trabalho além de competitivo é excludente para quem vive na periferia.

Ao fechar os canais de mobilidade social, os jovens da periferia veem obscurecidos seus projetos de futuro pela falta de emprego ou precarização e alta vulnerabilidade dos trabalhos existentes. Essas são marcas sociais das quais os jovens constroem rotas, trajetos e travessias de vida que nem sempre coincidem com projetos originais e, em muitos casos, se conformam nos campos da informalidade e ilegalidade gerados pela sociedade atual. A massificação do ensino e a generalização de diplomas têm criado elevadas expectativas de mobilidade social entre os jovens, mas muitos deles não podem desfrutar de status correspondentes aos títulos adquiridos. Daí a consequente frustração que atinge tantos deles. Alguns começam a estudar o que não desejam e acabam indo trabalhar naquilo que não gostam, outros estudam uma determinada área e terminam trabalhando em outra que não estudaram, ocasionando um desajustamento entre o nível de aspirações e as reais possibilidades de concretizações dessas aspirações.

Nos tempos atuais, a carreira profissional de um jovem não mais segue uma linearidade pré-determinada. As possibilidades de inserção profissional são múltiplas e diversas, pode-se ser qualquer coisa em qualquer tempo, como também se pode deixar de sê-lo para ser algo distinto logo depois.

Realmente, o futuro não existe, pois procurar conhecê-lo é supor que ele é conhecível, ou seja, que já se encontra determinado; no entan- 
to, ele ainda está por vir. Ainda que o pressentimento o afirme, trata-se de uma afirmação por antecipação. Somente a esperança permite suportar a espera de sua chegada, não sendo possível qualquer ação transformadora no mundo sem a esperança de um possível futuro. É preciso que os jovens das camadas menos favorecidas tenham o direito à esperança para que, operando no presente, tenham um futuro melhor, menos injusto. É preciso que saibam que suas vidas são construídas e que, apesar de constituída e constituinte da realidade, não existe um único caminho para o futuro. Há outras trilhas e direções a serem seguidas. Encontrar o novo, sabendo buscar no velho aquilo que permite estarem sempre reconstruindo perspectivas futuras.

A educação formal não garante uma mobilidade vertical ascendente nos tempos atuais, porém representa uma possibilidade diante das incertezas. As expectativas se estreitam, mas a esperança deve permanecer. As incertezas do futuro no século atual também geram respostas. Assim, do contexto fatalista, surge uma esperança como questionamento implícito na resignação: tem que haver um tempo, alguma oportunidade em que essa realidade vá se aliviando, essa situação não pode seguir sempre assim.

Se somos intrinsecamente curiosos/as e estamos condenados/as a conhecer, por que negar o trabalho educacional? As aprendizagens deverão tornar-se importantes pelo seu valor de uso, como forma de conhecer e intervir no mundo, e não pelo seu valor de troca, ou seja, pelos benefícios materiais e simbólicos prometidos pelo sistema de ensino para o futuro.

Recebido em 30 de maio de 2015 Aprovado em 29 de outubro de 2015

\section{Referências}

ARCE, José Manuel Valenzuela. Vida de Barro Duro: cultura popular juvenil e grafite. Rio de Janeiro: Editora UFRJ, 1999.

ARCE, José Manuel Valenzuela. El Futuro Ya Fue: socioantropologia de 1@s Jovens em la modernidade. Ciudad del México: Colégio de la Frontera Norte, 2009. BOGDAN, Robert; BIKLEN, Sari Knopp. Investigação Qualitativa em Educação. Porto: Porto, 1994.

CANÁRIO, Rui. A Escola: das “promessas” às “incertezas”. Revista Educação Unisinos, São Leopoldo, v. 12, n. 2, p. 73-81, maio/ago. 2008.

CARRANO, Paulo. Identidades Culturais Juvenis e Escolas: arenas de conflitos e possibilidades. Diversia, Valparaíso, v. 1, p. 159-184, abr. 2009. Disponível em: <http://www.cidpa.cl/wp-content/uploads/2013/05/Revista-Diversia-01.pdf>. Acesso em: 20 jul. 2013.

CEARÁ, Governo do Estado. Lei n 14.273, de 19 de dezembro de 2008. Dispõe sobre a criação das Escolas Estaduais de Educação Profissional - EEEP, no âmbito da Secretaria da Educação. Disponível em: <www.educacaoprofissional. seduc.ce.gov.br/>. Acesso em: 22 jul. de 2013. 
DAMASCENO, Maria Nobre (Org.). Entre o Sonho e a Realidade: educação e perspectivas de trabalho para os jovens. Fortaleza: Brasil Tropical, 2004.

DAYRELL, Juarez; CARRANO, Paulo Cesar. Os Jovens no Brasil: difíceis travessias de fim de século e promessas de um outro mundo. [S.I.]: Em Diálogo, 2003. Disponível em: <http://www.emdialogo.uff.br/sites/default/files/JOVENS_ BRASIL_MEXICO.pdf>.Acesso em: 23 jul. 2013.

DAYRELL, Juarez. A Escola "Faz" as Juventudes? Reflexões em torno da socialização juvenil. Educação \& Sociedade, Campinas, v. 28, n. 100, p. 1105-1028, out. 2007.

FURTER, Pierre. A Dialética da Esperança: uma interpretação do pensamento utópico de Ernst Bloch. Rio de Janeiro: Paz e Terra, 1974.

IBGE. Censo Demográfico 2010. Rio de Janeiro: IBGE, 2012.

LECCARDI, Carmen. Por um Novo Significado do Futuro: mudança social, jovens e tempo. Revista de Sociologia da USP, São Paulo, v. 17, n. 2, p. 35-57, 2005.

NOVAES, Regina. Os Jovens de Hoje: contextos, diferenças e trajetórias. In: ALMEIDA, Maria Isabel Mendes de; EUGÊNIO, Fernanda (Org.). Culturas Jovens: novos mapas do afeto. Rio de Janeiro: Zahar, 2006. P. 105-120.

OLIVEIRA, Ramon. A (Des)Qualificação da Educação Profissional Brasileira. São Paulo: Cortez, 2003.

PAIS, José Machado. Buscas de Si: expressividades e identidades juvenis (Prefácio). In: ALMEIDA, Maria Isabel Mendes de; EUGÊNIO, Fernanda (Org.). Culturas Jovens: novos mapas do afeto. Rio de Janeiro: Zahar, 2006. P. 7-21.

PAIS, José Machado. Culturas Juvenis. Lisboa: Imprensa Nacional, 2003.

POCHMANN, Márcio. Juventude em Busca de Novos Caminhos no Brasil. In: NOVAES, Regina; VANNUCHI, Paulo (Org.). Juventude e Sociedade: trabalho, educação, cultura e participação. São Paulo: Fundação Perseu de Abreu, 2004. P. 217-241.

RAMOS, Marise Nogueira. Educação Profissional: história e legislação. Curitiba: Instituto Federal Paraná Educação a Distância, 2011.

SALES, Celecina de Maria Veras. Os Jovens como Experimentadores e Produtores de Devires. In: DAMASCENO, Maria Nobre; MATOS, Kelma Lopes de; VASCONCELOS, José Gerardo (Org.). Trajetórias da Juventude. Fortaleza: LCR, 2001. P. 65-86

SALES, Celecina de Maria Veras. Cultura Juvenil e Perspectivas de Futuro de Jovens do Campo e da Cidade. Fortaleza: Relatório de Pesquisa, 2011. Mimeo.

SAVIANI, Dermeval. História das Ideias Pedagógicas no Brasil. Campinas: Autores Associados, 2011.

Celecina Veras Sales possui doutorado em Educação pela Universidade Federal do Ceará e Pós-Doutorado pelo Instituto de Ciências Sociais de Lisboa. Pesquisa e orienta sobre: Juventude, Gênero e Movimentos Sociais. É Professora Associada da Universidade Federal do Ceará do Curso de Graduação de Gestão de Políticas Públicas e da Pós-Graduação em Educação. E-mail: celecinavs@gmail.com

Maria Aurilene de Deus Moreira Vasconcelos é graduada em Pedagogia e Mestre em Educação pela Universidade Federal do Ceará/UFC. Pesquisa sobre juventude e ensino médio. É diretora da Escola Estadual de Educação Profissional Paulo Petrola desde sua implantação no Estado do Ceará. E-mail: aurilenededeus@hotmail.com 